\title{
BARREIRAS FÍSICAS E O ACESSO ÀS AULAS DE EDUCAÇÃO FÍSICA
}

\author{
Edison Martins Miron \\ Academia da Força Aérea, Pirassununga, São Paulo, Brasil \\ Maria da Piedade Resende da Costa \\ Universidade Federal de São Carlos, São Carlos, São Paulo, Brasil
}

\begin{abstract}
Resumo
O conceito "inclusão" tem sido amplamente discutido, mas para que se torne realidade necessita que toda a sociedade se adapte. O objetivo deste estudo foi descrever a situação das barreiras físicas existentes em escolas de um município do Estado de São Paulo, com relação ao ambiente pedagógico destinado às aulas de Educação Física (EF). Foram observados espaços como banheiro, salas de aula, calçadas, entre outros, de 29 escolas. A coleta de dados se deu através de um protocolo de observação. Os resultados demonstraram que apenas $13 \%$ das escolas permitem que a Pessoa com Deficiência Física (PDF) se locomova em seu interior sem auxílio, sendo apenas três as que possuem rotas alternativas de acesso. E ainda, 90\% das escolas não possuem condições físicas mínimas para oferecer à PDF um convívio adequação no contexto das aulas de EF.
\end{abstract}

Palavras chave: Deficiência Física. Acessibilidade. Educação Física. Barreiras Físicas.

\section{Introdução}

A educação é um processo do qual todos os indivíduos de uma sociedade deveriam participar durante seu desenvolvimento, como forma de qualificá-los para o aprendizado das questões referentes às interações conscientes e socialmente regulamentadas, que poderão auxiliá-los na busca de se tornarem independentes e responsáveis.

O advento da educação como direito de todos é dever da família e do Estado, e ela se faz obrigatória em nosso país a partir dos sete anos de idade, dentro do Ensino Fundamental da Educação Básica. Isso modifica o desenho existente até o final do século XX, trazendo para a escola alunos com 
características culturais, sociais, econômicas, psicológicas e particularidades especiais diferenciadas. Em contrapartida, toda a sociedade, e também a escola, não se prepararam adequadamente para atender com qualidade todos os seus novos e antigos alunos.

Saviani (2008) sinaliza este período como a face pedagógica da "inclusão excludente", onde alunos são incluídos no sistema escolar, em cursos de diferentes níveis e modalidades, sem os padrões de qualidade adequados. Stainback e Stainback (1999) observam que a escola é um agente disseminador da educação em seu sentido mais amplo, e tem papel preponderante na formação intelectual de seus alunos, devendo contribuir de forma efetiva neste aspecto, pois educação é uma questão de direitos humanos.

Como bem sugere Rodrigues (2006), a escola pública, de modo geral, para ter sucesso no advento da inclusão, precisa responder de forma apropriada e com alta qualidade não só à deficiência, mas a todas as formas de diferenças dos alunos. A partir da Conferência Mundial de 1994 da UNESCO - Declaração de Salamanca - Princípios, Política e Práticas sobre Necessidades Educacionais Especiais (UNESCO, 1994), fica claro que a escola e a sociedade em geral precisam se adequar, fazendo mudanças no seu contexto, para que possa ser possível a inclusão de todos os alunos no processo da educação.

Denari (2006) destaca a importância de o Estado não se eximir de assumir a responsabilidade pela educação, no que se refere ao tratamento especial e à natureza dos serviços a serem oferecidos às pessoas com deficiência, como parte importante no processo do ensino inclusivo resultante das modificações que a escola se dispuser a fazer.

A Constituição Federal Brasileira assume sua responsabilidade juntamente com a sociedade na questão da educação brasileira, no seu artigo 205:

\begin{abstract}
"A educação, direito de todos e dever do Estado e da família, será promovida e incentivada com a colaboração da sociedade, visando ao pleno desenvolvimento da pessoa, seu preparo para o exercício da cidadania e sua qualificação para o trabalho" (BRASIL, 2002, p.123).
\end{abstract}

É preciso, então, que a escola acompanhe a intensidade com que os novos valores e paradigmas se apresentam, de forma a garantir, ainda que minimamente, a equiparação de oportunidades e a igualdade de direitos que norteiam as ações humanas, nas quais todas as pessoas são valorativamente iguais.

O conceito de inclusão deve ser entendido como um processo gradual, que procura modificar os diferentes sistemas sociais existentes, dando

Pensar a Prática, Goiânia, v. 17, n. 2, p. 377-394, jan./mar. 2014 378 
nova direção quanto às questões de adaptação sociais relativas às pessoas com deficiência. Isso é exemplificado no conceito de Sassaki (1997, p.41):

Processo pelo qual a sociedade se adapta para poder incluir, em seus sistemas sociais gerais, pessoas com necessidades especiais e, simultaneamente, estas se prepararem para assumir seus papéis na sociedade. A inclusão social constitui, então, um processo bilateral no qual as pessoas, ainda excluídas, e a sociedade buscam, em parceria, equacionar problemas, decidir sobre soluções e efetivar a equiparação de oportunidades para todos.

No presente estudo, o tema inclusão vincula-se às questões relacionadas à inclusão escolar, ou seja, aos aspectos considerados importantes e necessários à pessoa com deficiência e que estão relacionados ao ambiente escolar.

O que se denomina atualmente de "inclusão" precisou atravessar diferentes fases, no que se refere às suas práticas sociais, de acordo com a evolução das sociedades e suas diferentes culturas. Isso também pode ser observado com relação ao atendimento do aluno com deficiência dentro do ambiente escolar.

$\mathrm{O}$ atendimento escolar que antes era totalmente segregado, começa a ser modificado, havendo maior preocupação na tentativa de "normalização do estilo de vida, dos ambientes e dos serviços" (WOLFENSBERGER, 1972) oferecidos à pessoa com deficiência, e que foi o chamado princípio da "normalização".

"Integração", termo utilizado posteriormente, nas décadas de 70 e 80, agregava novas formas de organização e de prestação de serviços. Assim, Deno (1970) propunha uma estrutura de atendimento (Sistema em Cascata) que poderia possibilitar uma mudança de nível para o aluno, buscando um grau maior de integração escolar com base nas potencialidades e no progresso do mesmo.

O debate mais profundo sobre inclusão educacional no Brasil tomou corpo a partir da Conferência Mundial de Educação para Todos, que se realizou em 1990, em Jomtien na Tailândia (CARVALHO, 1999). Ainda no que tange aos aspectos legais, a Lei de Diretrizes e Bases da Educação Brasileira LDBEN 9394/1996 - Lei Darcy Ribeiro (BRASIL, 1996), recomenda que a educação seja destinada também às pessoas com necessidades educacionais especiais, como pode ser observado através do seu artigo $4^{\circ}$. Item III: “atendimento educacional especializado gratuito aos educandos com necessida- 
des especiais, preferencialmente na rede regular de ensino" (BRASIL, 1996).

No contexto da educação geral, a Educação Física (EF) é disciplina obrigatória dentro do currículo escolar, sendo regida por normas e métodos que norteiam os seus objetivos, no sentido de contribuir com a educação integral das pessoas.

Maueberg-de Castro (2005) salienta que a EF é uma matéria como qualquer outra similar à leitura, aritmética, estudos sociais, biologia, e que irá diferir de acordo com a filosofia do professor. A autora ainda refere que, como área de conhecimento, a EF inclui disciplinas e fundamentos centrados no fenômeno corpo em movimento e suas bases biológicas, psicológicas e sociais.

Concordamos com Rodrigues (2003), que observa a importância da EF como disciplina curricular, salientando que a mesma não pode ficar indiferente mediante o movimento de Educação Inclusiva. Deve ser parte integrante do currículo oferecido pela escola.

Com relação à Pessoa com Deficiência Física (PDF), para este estudo, serão evidenciadas as questões da Deficiência Física (DF) e as principais dificuldades encontradas para o acesso, permanência e desenvolvimento de atividades diárias na escola, dentro do espaço da escola pública. Entendemos como PDF, conforme a definição de Silva (2006, p.17):

Diferentes condições motoras que acometem as pessoas comprometendo a mobilidade, a coordenação motora geral e da fala, em consequência de lesões neurológicas, neuromusculares, ortopédicas, ou más formações congênitas ou adquiridas.

Existem barreiras para qualquer pessoa, mas em especial para a PDF elas se tornam mais agravantes. Evidentemente, as barreiras existentes vão variar de acordo com a deficiência e poderão ser mais ou menos observadas, dependendo, entre outros aspectos, do grau de comprometimento dessa mesma deficiência.

A escola precisa, portanto, conhecer quais são as barreiras que os alunos com DF, eventualmente, possam enfrentar no acesso a estes ambientes, na participação do processo educacional e nas aulas de EF, procurando, assim, por meio de estratégias diversas, adequar sua permanência e desenvolvimento dentro da escola.

Dessa maneira, adotamos parte dos princípios estabelecidos pelo Ministério da Educação e do Desporto/MEC, no que diz respeito à normalização e à integração dos educandos no sistema regular de ensino como um dos

Pensar a Prática, Goiânia, v. 17, n. 2, p. 377-394, jan./mar. 2014 380 
pressupostos básicos da Política Nacional de Educação Especial (BRASIL, 1994). Esta política reflete a decisão do governo brasileiro de tratar a educação como uma questão de direito de todos.

Na questão da acessibilidade, como forma de uniformizar as normas brasileiras com relação a edificações, mobiliários, espaços e equipamentos urbanos, em 1994 é criada a Norma Brasileira - NBR 9050, que estabelece critérios e parâmetros técnicos a serem observados quando do projeto, construção, instalação e adaptação de edificações, mobiliário, espaços e equipamentos urbanos às condições de acessibilidade (ABNT, 2004). Tendo como referência essa política, o próprio MEC defende que existe a necessidade de se pensar numa "arquitetura acessível" voltada para todas as pessoas, contemplando, assim, as PDF (BRASIL, 2004).

Existem leis que estabelecem normas gerais e critérios para a promoção da acessibilidade das PDF. Entre elas: Lei n ${ }^{\circ} 10.048$, de 8 de Novembro de 2000, que dá prioridade ao atendimento às pessoas com deficiência; e Lei $\mathrm{n}^{\mathrm{o}} 10.098$, de 19 de Dezembro de 2000, que estabelece normas gerais e critérios básicos para a promoção da acessibilidade. Ambas foram regulamentadas pelo Decreto-lei 5296 de 2 de Dezembro de 2004. Estas Leis salientam algumas adequações que devem ser realizadas com o intuito de receber bem as pessoas com deficiência (BRASIL, 2004).

O Capítulo II, do Decreto-Lei 5296, trata do atendimento prioritário, e no Art. $5^{\circ}$ orienta os órgãos da administração pública direta, indireta, fundacional e as empresas prestadoras de serviços públicos, entre elas as escolas, indicando que os mesmos deverão dispensar atendimento prioritário às pessoas com deficiência ou com mobilidade reduzida (BRASIL, 2004).

Ainda no Decreto-Lei 5296, define-se o que é PDF ou com mobilidade reduzida, em substituição ao definido e previsto na Lei 10.690, de 16 de Junho de 2003. Assim, as pessoas que se enquadram dentro do conceito de DF serão aquelas que apresentem, de forma permanente ou temporária, as seguintes características:

\begin{abstract}
Alteração completa ou parcial de um ou mais segmentos do corpo humano, acarretando o comprometimento da função física, apresentando-se sob a forma de paraplegia, paraparesia, monoplegia, monoparesia, tetraplegia, tetraparesia, triplegia, triparesia, hemiplegia, hemiparesia, ostomia, amputação ou ausência de membro, paralisia cerebral, nanismo, membros com deformidade congênita ou adquirida, exceto as deformidades estéticas e as que não produzam dificuldades para o desempenho de funções (BRASIL, 2004 - Decreto-Lei 5296, Art. 5º Item A).
\end{abstract}

Pensar a Prática, Goiânia, v. 17, n. 2, p. 377-394, jan./mar. 2014 381 
O mesmo Decreto destaca também a questão das pessoas com Mobilidade Reduzida:

Pessoa com mobilidade reduzida, aquela que, não se enquadrando no conceito de pessoa portadora de deficiência, e, tenha por qualquer motivo, dificuldade de movimentar-se, permanente ou temporariamente, gerando redução efetiva da mobilidade, flexibilidade, coordenação motora e percepção. (BRASIL, 2004 - Decreto-Lei 5296, Art. $5^{\circ}$. Item A).

O Capítulo III do Decreto-Lei 5296, quanto ao acesso prioritário às edificações e serviços das instituições financeiras, deve seguir os preceitos estabelecidos no mesmo e nas normas técnicas de acessibilidade da Associação Brasileira de Normas Técnicas - ABNT. Mais especificamente, a NBR 9050/2004 - que fixa critérios de acessibilidade para pessoas com deficiências às edificações, espaço, mobiliário e equipamentos urbanos e a NBR/13994 - que fixa as condições exigíveis com relação aos elevadores de passageiros e elevadores para transporte de pessoa portadora de deficiência (BRASIL, 2004).

Os estudos de Lauand (2000), Moreira (2000), Luiz e Mandarino, (2003), Maciel e Mandarino, (2003) Orlandi, (2003), Aragão (2004), Souza Junior (2005), Lunaro (2006), Calado (2006), Tanoue (2006), Massari (2006), Keppe Junior (2007), demonstram que ainda deve ser percorrido um longo caminho na busca de garantir a equiparação de oportunidades e de acesso da pessoa com deficiência.

Lauand (2000) descreveu a acessibilidade de crianças com DF em escolas do Ensino Infantil e demonstrou que, embora algumas escolas possuam algum tipo de adaptação para favorecer o acesso e a circulação dos seus alunos, estas adaptações não permitem que o aluno com DF circule de maneira autônoma em todos os espaços que necessitaria estar durante o seu período dentro das mesmas.

$\mathrm{Na}$ área específica da EF, estudos como os de Luiz e Mandarino (2003), Maciel e Mandarino, (2003) procuraram observar os espaços de clubes e academias, e os espaços de lazer, respectivamente, em algumas cidades, com relação à acessibilidade física. Os resultados também demonstram que muito pouco tem sido feito no sentido de adequar espaços que garantam uma locomoção e sua utilização com um mínimo de autonomia.

Orlandi (2003) identificou e analisou as características físicas e ambientais mais importantes das calçadas, segundo a percepção dos usuários com DF ou com dificuldade de locomoção. Observou que os usuários em 
questão pouco se importam com as variáveis (conforto, segurança e condições ambientais) de caracterização dos aspectos de qualidade das calçadas prescritas pelos técnicos especialistas. Os resultados de sua pesquisa indicam que a necessidade de locomoção através dos diversos ambientes da cidade é tão grande, que faz com que as pessoas com dificuldade de locomoção apenas desejem ter à sua disposição ambientes que simplesmente permitam seu deslocamento autônomo.

Aragão (2004) identificou as barreiras arquitetônicas que dificultam o acesso da PDF aos serviços básicos de saúde e hospitais gerais, além de estudar as dificuldades de comunicação entre estas pessoas e membros da equipe de saúde. Seu estudo demonstrou que em todos os níveis de acesso existem barreiras que prejudicam ou impossibilitam o acesso aos serviços de saúde da PDF, alertando para o descaso do serviço público e dos profissionais da área de saúde do universo pesquisado.

Souza Junior (2005) evidenciou que o desenvolvimento de Leis de acessibilidade e as Políticas Públicas das mais variadas instâncias (municipal, estadual e federal) não são, por si só, garantia de que as adequações necessárias com relação às barreiras arquitetônicas serão realmente efetuadas. Ao analisar as políticas públicas da cidade de Natal - RN entre os anos de 1992 e 2002, com relação à acessibilidade, o autor evidencia que muito do que foi previsto não se traduziu em ações práticas por parte do poder público e da sociedade.

Lunaro (2006) analisou a percepção de idosos com relação à avaliação dos espaços urbanos de uma cidade do interior de São Paulo, e obteve dados semelhantes que demonstram que, para eles, o mais importante é a garantia de que possam caminhar com conforto e com autonomia e atravessar as ruas com segurança.

Ainda com relação à acessibilidade, Keppe Junior (2007) desenvolveu em seu estudo um índice que considera os parâmetros de maior importância sob o ponto de vista dos usuários de cadeira de rodas com relação às calçadas e a travessia das ruas. Os resultados demonstram que, conforme já haviam evidenciado Orlandi (2003) e Lunaro (2006), a maior preocupação está relacionada com o estado de conservação das calçadas e o tipo de piso utilizado. As demais variáveis existentes demandam menor preocupação por parte dos mesmos.

Pesquisas que podem servir de base para o estudo em questão foram as desenvolvidas por Moreira (2000) e Calado (2006). A primeira avaliou os ambientes escolares levando em consideração o conforto antropométrico e a acessibilidade no município do Rio de Janeiro. A autora observou que mesmo as escolas que foram projetadas ou reformadas para receber pessoas com deficiência não observam as normas vigentes. No segundo estudo, a respec- 
tiva autora observou e analisou a acessibilidade ao ambiente escolar de duas escolas municipais da cidade de Natal - RN. Foram utilizados diferentes instrumentos com o objetivo de identificar as adaptações e as condições de acessibilidade existentes nas instituições em questão.

Assim, para garantir a presença dos alunos com DF na escola e, consequentemente, nas aulas de EF, a acessibilidade dos mesmos para chegar até lá deve ser considerada. Também, deslocar os alunos para locais de uso público dentro da escola e participar de forma autônoma de todas as atividades envolvidas no processo educacional mostra a importância de se observar as necessidades existentes quanto à estrutura física e à utilização do espaço físico pelo aluno com deficiência. Isso, principalmente para a sua participação durante as aulas de EF.

Conforme o exposto, o objetivo do presente estudo foi descrever a situação das barreiras físicas existentes em escolas estaduais de um município do Estado de São Paulo, principalmente com relação ao ambiente pedagógico destinado às aulas de EF.

\section{Método}

Esta pesquisa se caracteriza como um estudo descritivo exploratório das condições atuais de acesso físico no âmbito escolar e, em particular, o acesso às instalações destinadas à prática da $\mathrm{EF}$.

Gil (1994) classifica este tipo de pesquisa como uma tentativa de proporcionar uma visão geral acerca de um determinado fato. Este trabalho tem como uma de suas possíveis finalidades fazer o levantamento de uma situação específica que se queira estudar, na tentativa da formulação de questões ou hipóteses para estudos posteriores.

\section{Local}

Escolas públicas estaduais de um município de porte médio do interior de São Paulo e que estão sob a responsabilidade da Secretaria de Estado da Educação, da Coordenadoria de Ensino e da Diretoria de Ensino de sua região. Coube a cada escola, em particular, na pessoa do seu Diretor (a), a opção de participação ou não na pesquisa.

\section{Universo do Estudo}

O universo do estudo foi constituído por 29 escolas, nos diversos distritos do município.

Pensar a Prática, Goiânia, v. 17, n. 2, p. 377-394, jan./mar. 2014 


\section{Instrumentos para a coleta de dados}

Foi elaborado de um protocolo adaptado do estudo de Calado (2006). Foram selecionados itens para serem observados conforme a NBR 9050 (ABNT, 2004). Os itens observados foram: 1) calçada; 2) acesso à edificação; 3) circulação interna; 4) ambientes. Para servir de apoio à observação e registrar os locais analisados foi utilizada uma câmera digital da marca Sony Ciber Shot 4.3.

\section{Procedimentos Iniciais}

1. Solicitação de autorização para o desenvolvimento do estudo junto à Diretoria de Ensino Regional do Município.

2. Solicitação de autorização e apresentação do estudo à Direção das escolas.

\section{Procedimentos para coleta de dados}

A coleta dos dados foi desenvolvida por meio do protocolo de observação e também pelo registro de fotografias dos mesmos, tendo a duração de três meses.

\section{Procedimento para análise dos dados}

Os dados foram analisados de forma comparativa, confrontando a realidade observada na pesquisa de campo com as normas da ABNT (NBR 9050/04) para os itens selecionados no protocolo desenvolvido. Os resultados estão dispostos de forma quantitativa. Os dados foram agrupados conforme as categorias já mencionadas anteriormente.

\section{Resultados e Discussão}

Dentre as 29 escolas visitadas, observou-se que apenas três delas foram construídas para serem acessíveis fisicamente, e que 48,37\% das mesmas já passaram por algum tipo de reforma na tentativa de se adequar às normas. Em $41,37 \%$ delas não houve nenhuma mudança física visando melhor adequação, como pode ser observado nos dados do Quadro 1.

Pensar a Prática, Goiânia, v. 17, n. 2, p. 377-394, jan./mar. 2014 385 
Quadro 1 - Acessibilidade nas 29 escolas observadas.

\begin{tabular}{|c|c|c|c|}
\hline $\begin{array}{c}\text { Escolas construí- } \\
\text { das para serem } \\
\text { acessíveis }\end{array}$ & $\begin{array}{c}\text { Escolas que já pas- } \\
\text { saram por adaptação } \\
\text { para serem acessí- } \\
\text { veis }\end{array}$ & $\begin{array}{c}\text { Escolas que não pas- } \\
\text { saram por reformas } \\
\text { de acessibilidade }\end{array}$ & Total \\
\hline 03 & 14 & 12 & 29 \\
\hline
\end{tabular}

Dentre as três escolas que foram construídas procurando atender às normas, duas delas não atendem a 100\% das adequações estabelecidas pela NBR 9050/2004.

No item analisado "calçada", observou-se que apenas uma, dentre as 29 escolas, apresenta todas as adequações. Os subitens analisados foram: largura mínima do passeio, conservação, existência de guias rebaixadas, mobiliário, vegetação e estacionamento exclusivo. Os resultados mostram que, embora a grande maioria possua área livre de passeio de acordo com as normas, a falta de conservação do piso das calçadas e a existência de vegetação situada dentro da área de passeio são os principais obstáculos encontrados. A Figura 1 mostra os dados encontrados para o estado de conservação das calçadas.

Calçadas em bom estado de conservação e sem obstáculos como mobiliário ou vegetação

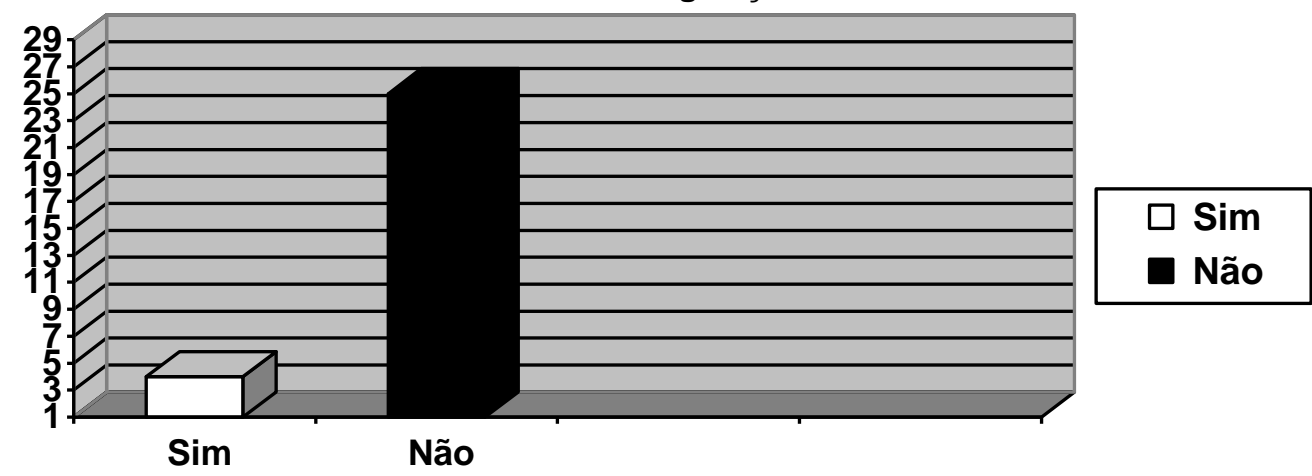

Figura 1 - Calçadas

Com relação ao "acesso à edificação", os subitens analisados foram: estado de conservação do piso, rampas de acesso, porta de entrada, tipo de maçaneta e a existência de vegetação atrapalhando o passeio. 
A Figura 2 mostra os dados que especificam se o passeio autônomo até a porta de entrada da escola é possível e se está de acordo com as normas. Os dados estão divididos em escolas que estão em acordo ou não com as normas vigentes.

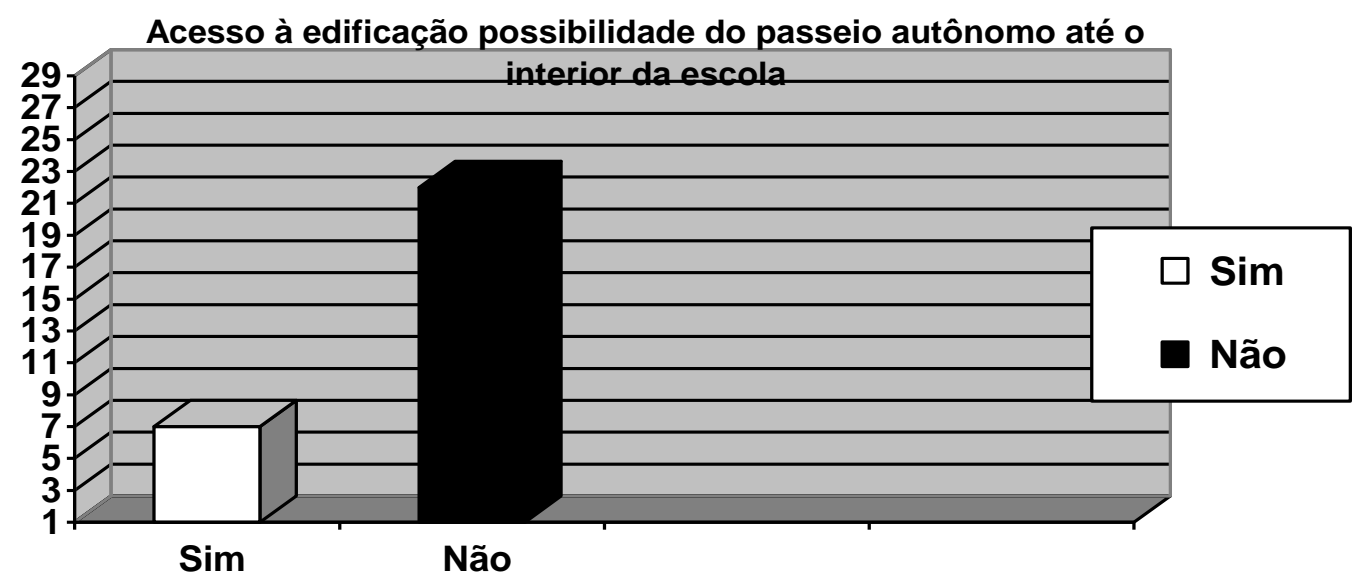

Figura 2 - Acesso à edificação

Em 75\% das escolas não seria possível o acesso à edificação de maneira totalmente autônoma por parte da PDF, sendo que, em apenas sete delas, uma PDF transitaria de forma adequada até a entrada da mesma.

Para o item relacionado à circulação interna e à necessidade ou não de rampas, elevador ou plataforma móvel para garantir uma circulação autônoma, a Figura 3 apresenta os dados observados. Os subitens analisados foram: estado de conservação e tipo de piso, recursos existentes para transposição de níveis padronizados e adequados, juntas e grelhas no passeio. Os dados foram divididos em escolas que possibilitam ou não a circulação interna de maneira satisfatória. Apenas em quatro das 29 escolas observadas e analisadas seria possível a circulação de uma PDF de maneira autônoma. 


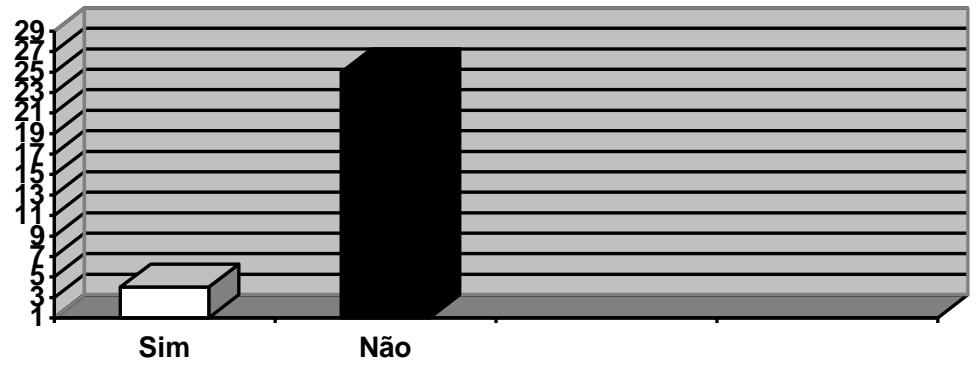

Figura 3 -Circulação Interna.

O espaço pedagógico "sala de aula" foi analisado através dos seguintes subitens: a) vão livre das portas e tipo de maçaneta; b) desnível ao acesso à sala; c) tipo e conservação do piso; d) tipo de janelas e acessórios; e) rota acessível até banheiro e bebedouro. Em quase metade das escolas (16 escolas) não existem rotas alternativas até as demais áreas pedagógicas, e 11 delas não possuem uma rota acessível até um banheiro ou bebedouro. Em apenas três das 29 escolas analisadas foi observada a adequação das salas de aula e a existência de rotas alternativas para banheiro e bebedouro.

Esse quadro dificulta a possibilidade de um aluno que faz uso de cadeira de rodas, por exemplo, ter condições mínimas de participação e permanência dentro da escola. A Figura 4 apresenta os resultados observados para o item "sala de aula": 
Salas de aula que atendem às normas e com rota alternativa para banheiro e

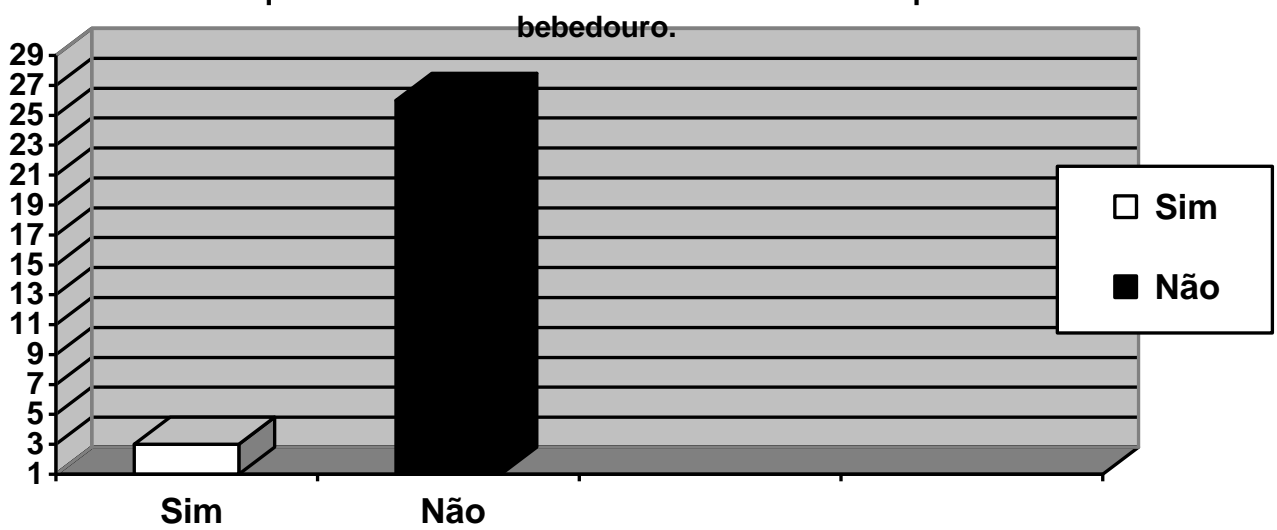

Figura 4 - Salas de aula.

Em consonância ao estudo de Calado (2006), observa-se que nem mesmo a sala de aula, espaço prioritário para a pessoa com deficiência, ou as rotas alternativas que favorecem a circulação da mesma para banheiros ou bebedouro, possuem adequação segundo as normas estabelecidas.

\section{Considerações Finais}

Nenhuma das 29 escolas analisadas atende a $100 \%$ das normas, demonstrando que o processo inclusivo ainda passa pela necessidade básica de adequação do seu principal espaço, a escola.

Nesse contexto, a acessibilidade física deve ser amplamente discutida, para que a escola possa realmente se tornar um espaço de tratamento igualitário e que colabore com os objetivos da inclusão. $\mathrm{O}$ combate às desigualdades passa pela observação das leis já existentes, uma vez que apenas a sua existência não garante o seu cumprimento. $\mathrm{O}$ direito de acesso da PDF aos bens sociais deve ter a escola como base da construção da cidadania.

Embora os preceitos da inclusão estejam sendo discutidos em todos os setores da sociedade, os resultados encontrados quanto à adequação do espaço físico esbarram não só na falta de ações concretas por parte do poder público, mas também na falta de conhecimento técnico das pessoas que estão envolvidas no ambiente escolar.

A aplicação das normas vigentes pode ser definidora no planejamento e execução de ações voltadas para a inclusão da PDF na escola. Entretanto, infelizmente, a maioria dos gestores de escolas não tem conhecimento das Normas de Acessibilidade ou acesso aos projetos das obras, dificultando 
sua participação decisiva como consultores ou fiscais de construções em andamento, o que poderia melhorar o atual quadro.

Através das observações fica claro que a manutenção das escolas é um ponto crítico e difícil de ser resolvido. A troca de um objeto ou a reforma de um espaço geralmente depende das licitações e demanda um tempo muito grande e, na maioria dos casos, os materiais de reposição utilizados não são adequados, pois não existem recursos financeiros compatíveis com as necessidades.

As escolas que possuem recursos como elevador, na sua maioria, não conseguem fazer a utilização dos mesmos por falta de manutenção. Este pode ser um dos motivos principais com relação à observação de que as escolas onde já foram efetuadas obras de adaptação, visando melhor acessibilidade física, ainda permanecem inadequadas para a utilização com condições mínimas por PDF e principalmente por cadeirantes.

\title{
PHYSICAL BARRIERS AND ACCESS TO PHYSICAL EDUCATION CLASSES
}

\begin{abstract}
The term "inclusion" has been widely discussed, but that becomes a reality requires that every society is adpte. The aim of this study was to describe the situation of physical barriers in the state schools in a municipality of the State of São Paulo, mainly in relation to the educational environment for the physical education classes (PE). Where observed spaces like bathrooms, classroons, sidewalk, among others, in 29 schools. Data collection was through an observation protocol. The results showed that access to the building, only $13 \%$ of schools allow a person with physical disabilities (PDF) to get around inside without assistance, being only three, those that have alternative routes of access, and yet, $90 \%$ of them do not possess the minimum physical conditions to offer a PDF conviviality adequacy in the context of PE classes.
\end{abstract}

Keywords: Disability. Accessibility. Physical Education. Physical Barriers.

\section{EBARRERAS Y ACCESO FÍSICO PARA LAS CLASES DE EDUCACIÓN FÍSICA}

\section{Resumen}

El término "inclusión" ha sido ampliamente discutido, pero que se convierte en una realidad cada sociedad debe adaptarse. El objetivo de este estudio fue describir la situación de las barreras físicas en las escuelas en un municipio del Estado de São Paulo, con respecto al ambiente educativo para las clases de Educación Física (EF). Se han observado ambientes en 29 escuelas. Los datos fueron colectados a través 
de un protocolo de observación. Los resultados mostraron que sólo el 13\% de las escuelas permite que una persona con discapacidad física (PDF) se locomova el interior sin ayuda, ya que sólo tres, los que tienen rutas alternativas de acceso, y, sin embargo, el $90 \%$ de ellos no tienen condiciones físicas mínimas para ofrecer adecuada convivencia PDF en el contexto de la EF.

Palabras-claves: Discapacidad, Accesibilidad, Educación Física, Barreras Físicas.

\section{Referências}

ABNT. Norma Técnica Brasileira NBR 9050. Acessibilidade e edificações, mobiliário, espaços e equipamentos urbanos, $2^{\mathrm{a}}$ ed., 2004.

ARAGÃO, A. E de A. Acessibilidade da pessoa portadora de deficiência física aos serviços hospitalares: Avaliação das barreiras arquitetônicas. Dissertação de Mestrado, Universidade Federal do Ceará - UFC/PPGE, Fortaleza, 104 p., 2004.

BRASIL. Constituiçãa (1988) Constituição da República Federativa do Brasil: Texto constitucional promulgado em 5 de outubro de 1988, com as alterações adotadas pelas Emendas Constitucionais Nos. 1/92 a 38/2002 e pelas Emendas Constitucionais de Revisão nos. 1 a 6/94. 427p. Brasília: Senado Federal - Subsecretaria de Edições Técnicas, 2002.

BRASIL. Ministério da Educação e do Desporto. Lei de Diretrizes e Bases da Educação Nacional. Lei no 9.394/96, Brasília, 1996.

BRASIL. CORDE/DEE-MEC Subsídios para a Elaboração da política Nacional para a Integração das Pessoas Portadoras de Deficiência no Sistema Regular de Ensino. Brasília: coordenação Nacional para Integração da Pessoa Portadora de Deficiência do Ministério da Ação Social/Departamento de Educação Especial do Ministério da Educação, 1994.

BRASIL. Casa Civil. Decreto No. 5296, de 2 de dezembro de 2004. Regulamenta as Leis Nos. 10.048, de 08 de novembro de 2000, que dá prioridade de atendimento às pessoas que especifica, e 10.098, de 19 de dezembro de 2000, que estabelece normas gerais e critérios básicos para a promoção da acessibilidade das pessoas portadoras de deficiência ou com mobilidade reduzida, e dá outras providências.

Pensar a Prática, Goiânia, v. 17, n. 2, p. 377-394, jan./mar. 2014 391 
CALADO, G. C. Acessibilidade no ambiente escolar: reflexões com base no estudo de duas escolas municipais de Natal - RN. 116p. 2006. Dissertação (Mestrado em Arquitetura e Urbanismo). Programa de Pós-Graduação em Arquitetura e Urbanismo. Universidade Federal do Rio Grande do Norte, 2006.

CARVALHO, R. E. Integração e Inclusão: do que estamos falando. In: Salto para o Futuro, Educação Especial: tendências atuais. Secretaria de Educação a Distância. Brasília: Ministério da Educação, SEED, 1999.

DENARI, F. E. (Artigo) In: RODRIGUES, D. (Org.) Inclusão e educação: doze olhares sobre a educação inclusiva, São Paulo, Summus, 2006.

DENO, E. Special education as developmental capital. Exceptional Children, n. 37, p.229-237, 1970.

GIL, A. C. Métodos e técnicas de pesquisa social. São Paulo: Editora Atlas, 1994.

KEPPE JUNIOR, C. L. G. Formulação de um indicador de acessibilidade das calçadas e travessias. Dissertação de Mestrado. PPGEU/UFSCar, 152f. São Carlos, 2007.

LAUAND, G. B. do A., Acessibilidade e formação continuada na inserção escolar de crianças com deficiências físicas e múltiplas/ Dissertação de Mestrado, UFSCar/PPGEEs, São Carlos, 121p., 2000.

LUIZ, É. M. F. e MANDARINO, C. M. Condições de Acessibilidade dos Cadeirantes no Município de Minas do Leão: Um Estudo Descritivo-Exploratório. UNISINOS - São Leopoldo - RS - Brasil. In: Revista da Sobama, Temas livre, Vol. 8, n.1, p.8 Dezembro 2003.

LUNARO, A. Avaliação dos espaços urbanos segundo a percepção de pessoas idosas. Dissertação de Mestrado. UFSCar/PPGEU, São Carlos, 107p. 2006.

MACIEL, R. R. G. e MANDARINO, C. M. Acessibilidade para Cadeirantes e Cegos em Clubes e Academias do Município de São Leopoldo: Um Estudo Descritivo-Exploratório UNISINOS - São Leopoldo - RS - Brasil. In: Revista da Sobama, Temas livre, Vol. 8, n.1, p.8 Dezembro 2003. 
MASSARI, S. A. As pessoas com deficiência Física ou visual e a acessibilidade urbana em Santo André - SP. 85p. 2006. Dissertação (Mestrado em Serviço social) Pontifícia Universidade católica de São Paulo, 2006.

MAUERBERG de CASTRO, E. Atividade Física Adaptada. Ribeirão Preto: Tecmed, 2005.

MOREIRA, A. DE A. M. Arquitetura Inclusiva: um estudo de escolas municipais do rio de janeiro. Dissertação de Mestrado, UFRJ/ Arquitetura 158p., Rio de Janeiro, 2000.

ORLANDI, S. C., Percepção do portador de deficiência física com relação à qualidade dos espaços de circulação urbana. Dissertação de Mestrado, PPGEEs, UFSCar, 130p. São Carlos, 2004.

RODRIGUES, D. A Educação Física Perante A Educação Inclusiva: Reflexões Conceptuais e Metodológicas. In: Revista da Educação Física/UEM Maringá, v. 14, n. 1, p. 67-73, 1. sem. 2003.

RODRIGUES, D. Inclusão e educação: doze olhares sobre a educação inclusiva /David Rodrigues (org.), São Paulo: Summus, 2006.

SASSAKI, Romeu Kazumi. Inclusão; Rio de Janeiro: WVA, 1997.

SAVIANI, D. História das idéias pedagógicas no Brasil. 2a . Ed, Campinas, Autores Associados, 2008.

SILVA, Adilson Florentino et al. A inclusão escolar de alunos com necessidades educacionais especiais: deficiência física. Brasília: Ministério da Educação, Secretaria de Educação Especial, 2006.

SOUZA JUNIOR, R. A. de. Avaliação da política pública de acessibilidade no período de 1992 a 2002 na cidade de Natal. Dissertação de Mestrado. UFRGN/PPGAU, 173p. Natal, 2005.

STAINBACK, S.; STAINBACK, W. Inclusão: um guia para educadores. Porto alegre: Artmed, 1999.

TANOUE, S. H. Espaços públicos abertos de circulação de pedestres e o usuário cadeirante. Tese de Doutorado, USP - FAU, 122p. São Paulo, 2006. 
UNESCO - Organização das Nações Unidas para a Educação, Ciência e Cultura / Ministério da Educação e Ciência da Espanha / Coordenadoria Nacional para Integração da Pessoa Portadora de Deficiência - Corde: Declaração de Salamanca e linha de ação sobre necessidades educativas especiais, Brasília, 1994.

WOLFENSBERGER, W. The principle of normalization in human services. Toronto: National Institute on Mental Retardation, 1972.

Recebido em: 29/04/2013

Revisado em: 09/09/2013

Aprovado em: 18/03/2014

Endereço para correspondência:

emmiron@terra.com.br

Edison Martins Miron

Academia da Força Aérea.

Estrada de Aguaí s/n

13631-972 - Pirassununga, SP - Brasil

Pensar a Prática, Goiânia, v. 17, n. 2, p. 377-394, jan./mar. 2014 